\title{
Retraction: Trapping mosquitoes using milk products as odour baits in western Kenya
}

Eunice A Owino

\section{Retraction}

This article [1] has been retracted by the Editor because there are unresolved issues relating to authorship and content.

Received: 25 August 2010 Accepted: 25 August 2010

Published: 25 August 2010

\section{Reference}

1. Owino AEunice: Trapping mosquitoes using milk products as odour baits in western Kenya. Parasites \& Vectors 2010, 3:55.

doi:10.1186/1756-3305-3-78

Cite this article as: Owino: Retraction: Trapping mosquitoes using milk products as odour baits in western Kenya. Parasites \& Vectors 2010 3:78.

Submit your next manuscript to BioMed Central and take full advantage of:

- Convenient online submission

- Thorough peer review

- No space constraints or color figure charges

- Immediate publication on acceptance

- Inclusion in PubMed, CAS, Scopus and Google Scholar

- Research which is freely available for redistribution

Submit your manuscript at www.biomedcentral.com/submit
C Biomed Central 